\title{
Irisin Protects Against Hind Limb Ischemia Reperfusion Injury
}

\author{
Ayșegül Küçük (iD) ${ }^{l, *}$ \\ Yücel Polat ${ }^{2}$ \\ Aydan Kılıçarslan $\mathbb{D}^{3}$ \\ Nuran Süngü ${ }^{3}$ \\ Hakan Kartal $\mathbb{D}^{4}$ \\ Ali Doğan Dursun $\mathbb{1}^{5, *}$ \\ Mustafa Arslan $\mathbb{1 D}^{6}$ \\ 'Kutahya Health Sciences University, \\ Medical Faculty, Department of \\ Physiology, Kutahya, Turkey; ${ }^{2}$ Mehmet \\ Akif Ersoy Thoracic and Cardiovascular \\ Surgery Training and Research Hospital, \\ Department of Cardiovascular Surgery, \\ Istanbul, Turkey; ${ }^{3}$ Yildirim Beyazit \\ University, Medical Faculty, Department \\ of Pathology, Ankara, Turkey; ${ }^{4}$ Gulhane \\ Medical Faculty, Gulhane Education and \\ Research Hospital, Department of \\ Cardiovascular Surgery, Ankara, Turkey; \\ ${ }^{5}$ Atilim University, Medical Faculty, \\ Department of Physiology, Ankara, \\ Turkey; ${ }^{6}$ Gazi University, Medical Faculty, \\ Department of Anesthesiology and \\ Reanimation, Ankara, Turkey \\ *These authors contributed equally to \\ this work
}

This article was published in the following Dove Press journal:

Drug Design, Development and Therapy

\begin{abstract}
Aim: The aim of this study was to evaluate the effects of irisin in a murine model of hind limb ischemia reperfusion (I/R).

Methods: The mice were divided into four groups $(\mathrm{n}=6$ in each group): control, irisin, ischemia reperfusion (I/R), and irisin-ischemia reperfusion (I-I/R). Irisin $\left(0.5 \mu \mathrm{g} . \mathrm{g}^{-1}\right.$, intraperitoneally [i.p.]) was administered $30 \mathrm{~min}$ before the $\mathrm{I} / \mathrm{R}$ procedure. After $2 \mathrm{~h}$ of ischemia and $2.5 \mathrm{~h}$ of reperfusion, blood and tissue samples were taken for biochemical and histopathological analysis. The results were analyzed by Kruskal-Wallis and Mann-Whitney $U$-tests.
\end{abstract}

Results: There was a statistically significant difference in the total antioxidant status (TAS) and total oxidant status (TOS) levels in all the groups. The TAS level in the I/R group was significantly lower than that in the control, irisin, and I-I/R groups, whereas the TOS level was significantly higher in the I/R group as compared with that in the other groups. Caspase3 activity and caspase- 8 activity, indicators of inflammation, were significantly higher in the $\mathrm{I} / \mathrm{R}$ and $\mathrm{I}-\mathrm{I} / \mathrm{R}$ groups as compared with those in the control and irisin groups.

Conclusion: Irisin may have protective effects in skeletal muscle ischemia reperfusion injury.

Keywords: irisin, ischemia reperfusion, caspase-3, caspase-8, mice

\section{Introduction}

Ischemia is the occurrence of cell death as a result of inadequate perfusion due to a decrease in the tissue blood supply. Reperfusion is the resumption of blood flow. In this period, secondary metabolites, such as oxygen free radicals, are produced. ${ }^{1}$ Oxygen free radicals are toxic under various clinical conditions. ${ }^{2}$ The production of oxygen free radical during reperfusion can lead to multiorgan failure, followed by local edema and muscle necrosis. ${ }^{3-5}$ Irisin is a recently identified hormone with 112 amino acids $(12,587 \mathrm{kDa}){ }^{6}$ It is a product of type I membrane protein cleavage encoded by the fibronectin type III domain containing 5 (FNDC5) gene. ${ }^{7}$ Irisin is secreted mainly in skeletal muscle and cardiac muscle. Irisin has several pharmacological effects, such as antioxidant, ${ }^{8}$ antiapoptotic, ${ }^{9,10}$ anti-inflammatory, ${ }^{11,12}$ neuroprotective, ${ }^{13}$ and hepatoprotective. ${ }^{14}$ It also has bone loss prevention effects. ${ }^{15}$

After reperfusion of ischemic tissues, cellular damage is a common and critical

Correspondence: Mustafa Arslan Gazi University, Medical Faculty, Department of Anesthesiology and Reanimation, Ankara, 06510, Turkey Tel +90 3I2 2026739

Email mustarslan@gmail.com clinical incident. Caspases, especially caspase-8, are proteases that initiate and execute apoptotic cell death. ${ }^{16}$ In the presence of increased inhibition of caspase8 , sensitivity to death receptors increases. Caspase- 3 is another protease that interacts with caspase- 8 and caspase- 9 in apoptosis. 
The aim of the study was to investigate the effect of irisin in a rodent model of hind limb muscle ischemia/ reperfusion (I/R) injury.

\section{Materials and Methods}

This study was performed in accordance with the guidelines of the National Institutes of Health on animal research, and it was approved by the animal experiments local ethics committee of Gazi University.

This study used 24 mice weighing $35-45 \mathrm{~g}$. The animals were housed in polycarbonate cages and maintained at $24^{\circ} \mathrm{C}$ under a 12 -h light/12-h dark cycle. Access to food was restricted 2 hours before the anesthesia procedure.

The animals were assigned to four groups $(n=6$ in each group): control, irisin, $\mathrm{I} / \mathrm{R}$, and irisin-I/R (I-I/R). In the control group, a midline laparotomy was performed without any additional surgical interventions. In the irisin group, the same procedures were applied as in the control group. $\% 0.9$ saline was used to prepare a $1 \%$ solution of irisin. Thirty minutes before ischemia, $0.5 \mu \mathrm{g} . \mathrm{g}^{-1}$ irisin (Sigma-Aldrich Co. Ltd.) was administered intraperitoneally (i.p.). A midline laparotomy was performed in the same way in the $\mathrm{I} / \mathrm{R}$ group. During the ischemic period, the infrarenal aorta was clamped for $2 \mathrm{~h}$. The clamp was then removed, and the tissue was reperfused for $2.5 \mathrm{~h}$. In the I-I/R-group, irisin was administered $30 \mathrm{~min}$ before ischemia. The group was then subjected to $2 \mathrm{~h}$ of ischemia and $2.5 \mathrm{~h}$ of reperfusion as in the other groups.

At the end of the experiments, blood samples and tissue samples were taken for biochemical and histopathological analysis. All the mice were then sacrificed.

\section{Biochemical Analysis Homogenization of Tissues}

The hind limb tissue collected in the Eppendorf tube frozen immediately in liquid nitrogen, and stored at $-80^{\circ}$ $\mathrm{C}$ in a deep freezer until the time of the total antioxidant status (TAS), total oxidant status (TOS), and oxidative stress index analyses. The procedures were done very quickly so the tissues were not allowed to thaw. First, pieces of $80-100 \mathrm{mg}$ weight were cut with 22 lancets (PLUSMED $^{\circledR}$ ) from the hind limb tissues weighed on a precision scale. $80-100 \mathrm{mg}$ weighted tissue was smashed in a porcelain bowl in the presence of liquid nitrogen, and powdered tissue was immediately transferred to a homogenization tube (099C S3, Glas-Col). $140 \mathrm{mM}$ $\mathrm{KCl}$ solution was added per gram of tissue to achieve a $1 / 10(w / v)$ dilution. In order not to increase the temperature, the homogenization tube was placed in a flake-ice-filled glass beaker. Glas-Col $\left(\mathrm{K} 5424^{\circledR}\right)$ homogenizer was used at a speed of $50 \mathrm{rpm}$ for $2 \mathrm{~min}$ to complete the process (pestle, 099C S21G, Glas-Col). Homogenates were transferred to $1.5 \mathrm{~mL}$ Eppendorf tubes and centrifuged at $3000 \mathrm{rpm}$ for 10 minutes (NF 048, NUVE). The supernatants obtained were transferred to new Eppendorf tubes.

\section{Measurements of Total Antioxidant Status/Total Oxidant Status \\ TAS Measurement}

TAS test kit (RelAssay Diagnostic ${ }^{\circledR}$, Turkey) was used according to the manufacturer's instructions to measure the TAS levels. $30 \mu \mathrm{L}$ of the sample was mixed with 500 $\mu \mathrm{L}$ of measurement buffer (reagent 1) in an Eppendorf tube. $2 \mu \mathrm{L}$ of that mixture was used to measure the absorbance at $660 \mathrm{~nm}$ (A1) (NanoDrop ${ }^{\circledR}$ ONE, Thermo Scientific). Then, $75 \mu \mathrm{L}$ of colored 2,2-azino-bis-3-ethylbenzothiazoline-6-sulfonic acid (ABTS) (reagent 2) was added to the mixture, and an incubation performed at $37^{\circ}$ $\mathrm{C}$ for $5 \mathrm{~min}$ (ST 30, NUVE). A2 measurement was evaluated at the absorbance of $660 \mathrm{~nm}$. Trolox Eq solution at a concentration of $1 \mathrm{mmol} / \mathrm{L}$ was used instead of samples to obtain the standard values. A1 and A2 measurements were done three times for each of the samples, and the average values were calculated. The absorbance change $(\triangle \mathrm{Abs})$ was calculated by subtracting the first absorbance value $\left(\mathrm{A}_{1}\right)$ from the second absorbance value $\left(\mathrm{A}_{2}\right)$. The TAS level was calculated using the formula given in the kit and expressed as mmol Trolox Eq/L.

TAS $=([\Delta \mathrm{AbsH} 2 \mathrm{O}-\Delta \mathrm{Abs}$ sample $] /[\Delta \mathrm{Abs} \mathrm{H} 2 \mathrm{O}-$ $\Delta$ Abs standard]).

\section{TOS Measurement}

TOS test kit (RelAssay Diagnostic ${ }^{\circledR}$, Turkey) was used according to the manufacturer's instructions to measure the TOS levels. $75 \mu \mathrm{L}$ of the sample was mixed with $500 \mu \mathrm{L}$ of measurement buffer (reagent 1) in an Eppendorf tube. $2 \mu \mathrm{L}$ of that mixture was used to measure the absorbance at 530 nm (A1) (NanoDrop ${ }^{\circledR}$ ONE, Thermo Scientific). Then, 25 $\mu \mathrm{L}$ of Pro-chromogenic solution (reagent 2) was added to the mixture, and an incubation performed at $37^{\circ} \mathrm{C}$ for $5 \mathrm{~min}$ (ST 30, NUVE). A2 measurement was evaluated at the absorbance of $530 \mathrm{~nm}$. A standard solution containing 10 $\mu \mathrm{mol} / \mathrm{L}$ of hydrogen peroxide $\left(\mathrm{H}_{2} \mathrm{O}_{2}\right)$ equivalent/liter given in the kit was used for standard measurement. A1 and A2 measurements were done three times for each of the 
samples, and the average values were calculated. The absorbance change ( $\triangle \mathrm{Abs}$ ) was calculated by subtracting the first absorbance value $\left(A_{1}\right)$ from the second absorbance value $\left(A_{2}\right)$. The TOS level was calculated using the formula given in the kit and expressed as mmol $\mathrm{H}_{2} \mathrm{O}_{2} \mathrm{Eq} / \mathrm{L}$.

$\mathrm{TOS}=([(\Delta$ Abs sample $] /[\Delta$ Abs standard $]) \times$ standard concentration $[10 \mu \mathrm{mol} / \mathrm{L}])$.

\section{Immunohistochemical Analysis}

Following tissue collection, the samples were fixed in formalin, embedded in paraffin blocks, and cut into sections $4 \mu \mathrm{m}$ thick. The cut tissue samples were then placed on slides coated with poly-L-lysine. The slides were kept in a humid medium at $45^{\circ} \mathrm{C}$ for one night and then transferred to another medium at $75^{\circ}$ for 20 min. Leica Bond-Max auto-stainer was used for deparaffinization after caspase- 8 and caspase- 3 antibodies were stained. The stained slides were covered with a cover slip with mounting medium and examined under a light microscope. The intensity of cytoplasmic localized caspase- 3 and caspase- 8 in muscle and endothelial cells were evaluated at 40 and $100 \times$ magnifications. The slides were evaluated by a pathologist who was blind to the study. The staining was scored as follows: $0=$ no staining, $1=$ mild staining, and $2=$ intense staining. The inclusion and evaluation criteria were to be stained with antibodies at least $50 \%$. Routine staining with hematoxylin-eosin dye, followed by examination under a light microscope was used to detect possible morphological changes.

\section{Statistical Analysis}

Statistical analysis was performed using the Statistical Package for the Social Sciences (SPSS, Chicago, IL, USA) 20.0 program. The Kolmogorov-Smirnov test was used for the comparisons of all variable groups. The results were analyzed using the Kruskal-Wallis test, with a Bonferroni-adjusted Mann-Whitney $U$ post hoc test. The results were expressed as the mean \pm standard error (SE). A value of $p<0.05$ was considered statistically significant.

\section{Results \\ Biochemical Findings}

There was a statistically significant difference in the TAS levels in all the groups $(p=0.034)$. The TAS level in the I/ $\mathrm{R}$ group was significantly lower than that in the control, irisin, and I-I/R groups (respectively, $p=0.045, p=0.015$, and $p=0.011$ ) (Figure 1).

Similar to the TAS levels, there was a statistically significant difference in TOS levels in all the groups $(p=0.002)$. The TOS level was significantly higher in the I/R group as compared with that in the control, irisin, and I-I/R groups (respectively, $p=0.007, p=0.008$, and $p=0.009$ ) (Figure 1).

\section{Histopathological Findings}

There was a statistically significant between-group difference in myositis caspase- 8 activity $(p=0.006)$. Myositis caspase-8 enzyme activity was significantly higher in the I/ $\mathrm{R}$ and $\mathrm{I}-\mathrm{I} / \mathrm{R}$ groups ( $p=0.003$ for both) as compared with those in the control and irisin groups $(p=0.032$ and $p=$ 0.032, respectively) (Figures 2-4).

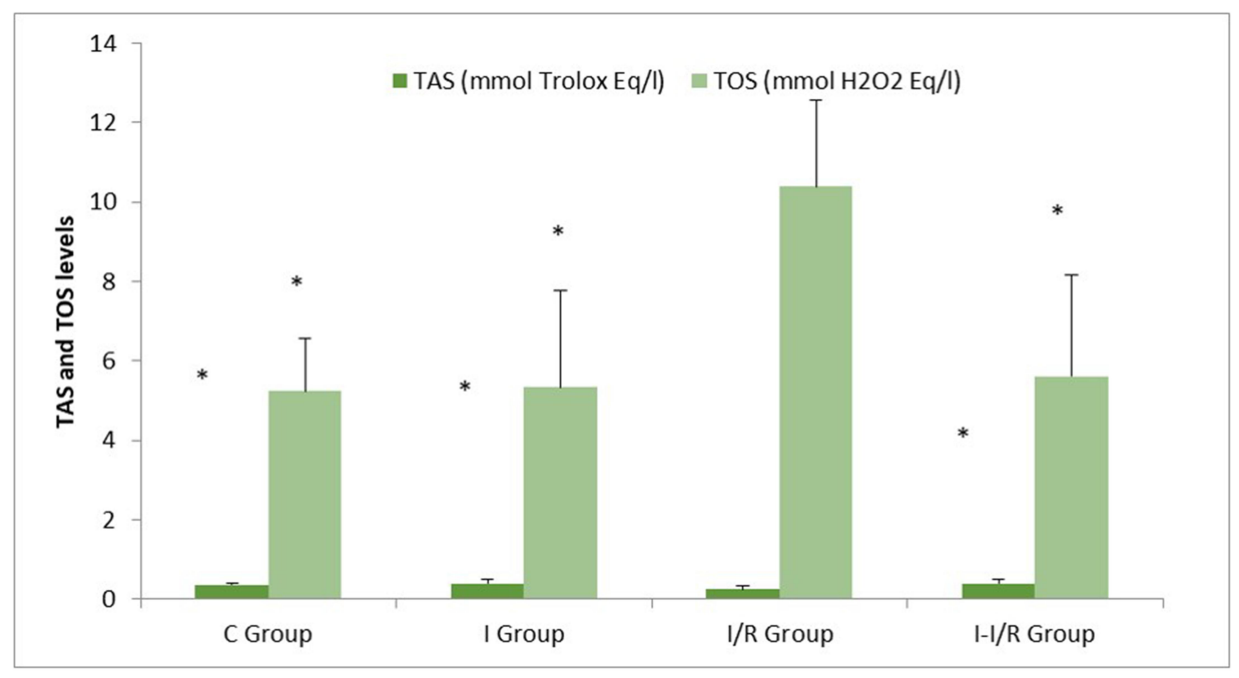

Figure I Total antioxidant status (TAS) and total oxidative status (TOS) levels (Mean \pm SE) $* p<0.05$ : Compared with I/R group. 


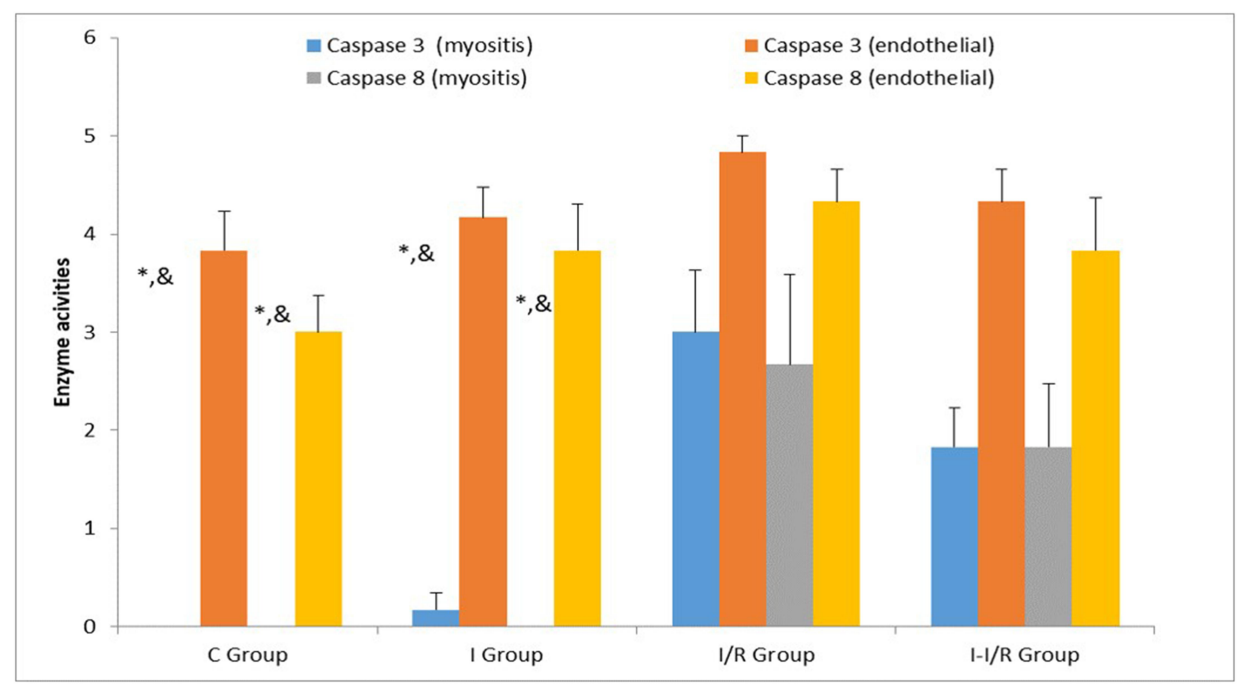

Figure 2 Caspase 3 and 8 enzyme activities (Mean \pm SE). ${ }^{*}<<0.05$ : Compared with I/R group; ${ }^{\&}<<0.05$ : Compared with I-I/R group.

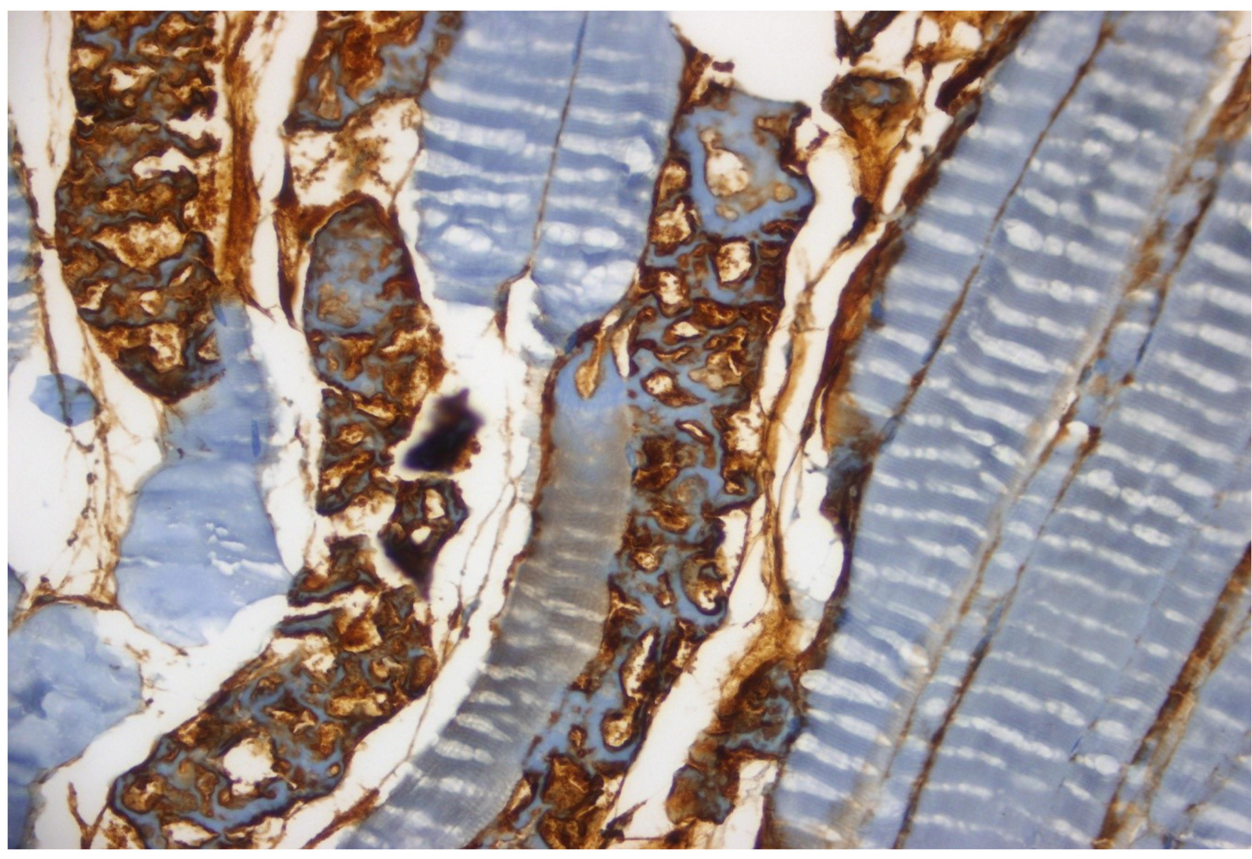

Figure 3 Remarkable caspase-8 staining is seen in muscle fibers and more than fifty percent of the vascular endothelium in I/R group (HE, 40x).

Similarly, there was a statistically significant between-group difference in myositis caspase-3 activity $(p<0.0001)$. Myositis caspase-3 enzyme activity was significantly higher in the $\mathrm{I} / \mathrm{R}$ and $\mathrm{I}-\mathrm{I} / \mathrm{R}$ groups $(p<$ 0.0001 for both) as compared with those in the control and irisin groups ( $p=0.003$ and $p=0.006$, respectively) (Figure 2).

Inflammation was significantly higher in the $I / R$ group as compared with that in the control, irisin, and
$\mathrm{I}-\mathrm{I} / \mathrm{R}$ groups $(p=0.007, p=0.037$, and $p=0.037$, respectively).

Myositis damage was significantly higher in the $I / R$ group as compared with that in the control, irisin, and $\mathrm{I}-\mathrm{I} /$ $\mathrm{R}$ groups (respectively, $p<0.0001, p=0.022$, and $p<$ 0.0001 ) (Table 1, Figures 5 and 6).

Congestion was significantly higher in the $\mathrm{I} / \mathrm{R}$ group as compared with that in the control and irisin groups $(p<0.001$ and $p<0.0001$, respectively) (Table 1, Figures 5 and 6). 


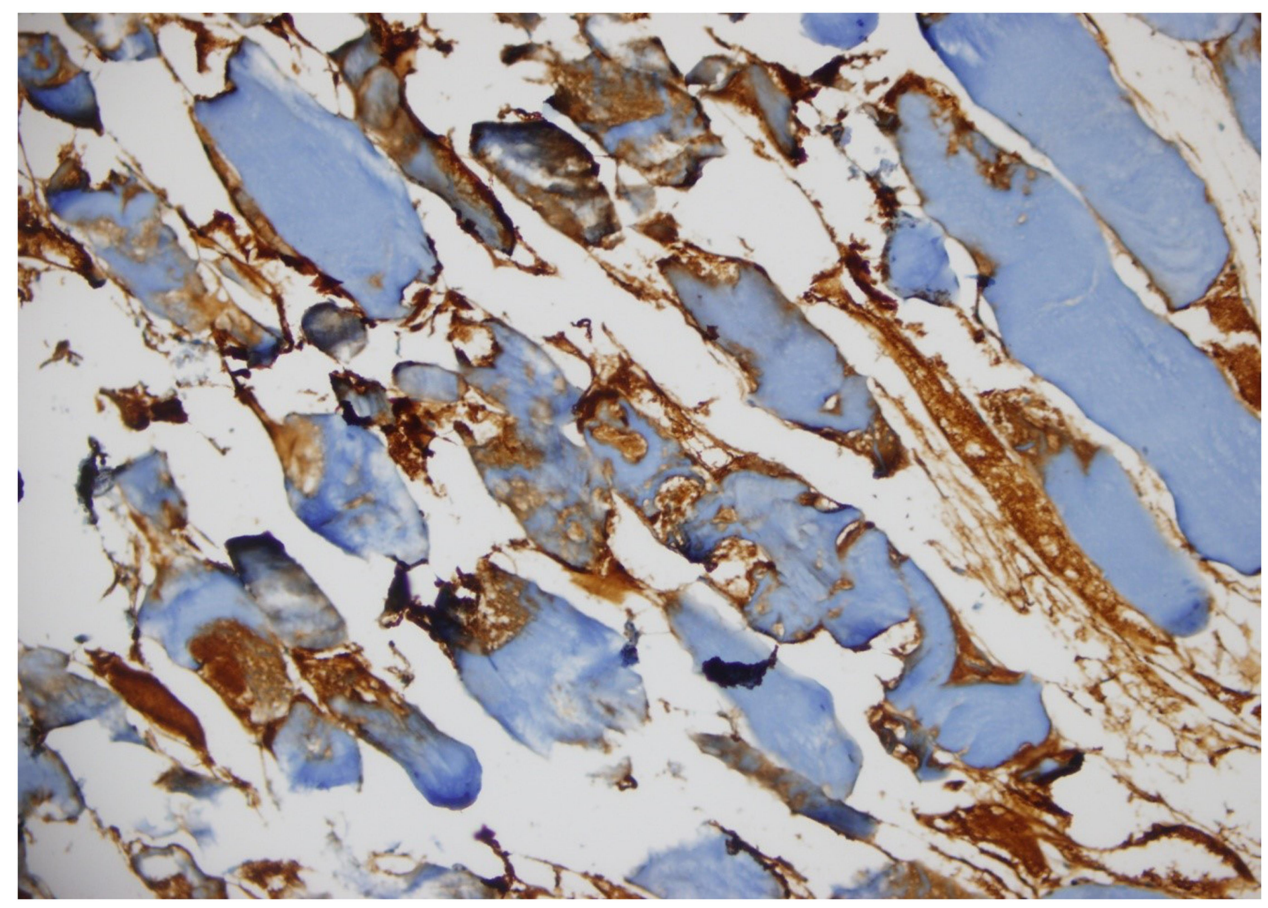

Figure 4 There is a medium caspase- 8 staining intensity in some parts of the muscle fibers and in less than half of the vascular endothelial regions in I-I/R group (HE, $40 \mathrm{x}$ magnification).

\section{Discussion}

Irisin is a PGC1- $\alpha$-dependent myokine, which can transform white adipose tissue into brown adipose tissue. ${ }^{7}$ It is the product of a transmembrane protein transcribed from the FNDC5 gene $^{17,18}$ and is mainly secreted by skeletal muscle and myocardium during exercise. ${ }^{19}$ Previous research reported that irisin reduced oxidative/nitrative stress and protected endothelial cells in type 2 diabetes. $^{7}$ Studies also reported that irisin provided protection against liver, cardiac, and perforator flap I/R. ${ }^{8,20-22}$ In addition, irisin was reported to play an important role in limb remote ischemic preconditioning-mediated lung protection by improving mitochondrial function. ${ }^{22}$

Ischemia is the most common cause of irreversible cellular injury. $\mathrm{I} / \mathrm{R}$ results in the generation of toxic reactive oxygen species (ROS) in organs. Ischemia studies reported irisin reduced the activity of cellular defense enzymes against ROS and reperfusion and that these oxidative products disturbed the delicate balance of oxidants/ antioxidants, leading to intracellular calcium overload, adenosine triphosphate depletion, myocardial apoptosis, and endothelial dysfunction. ${ }^{23-27}$ Research also demonstrated that oxidative products, such as ROS, reactive nitrogen species, lipid peroxides, hydrochloric acid, and malondialdehyde (MDA), formed TOS. ${ }^{1}$

In the present study, in light of this information, we investigated whether irisin ameliorated $\mathrm{I} / \mathrm{R}$-induced damage by measuring TAS and TOS levels in a murine model of I/R injury. Previous studies showed that measurements of TAS levels provided more valuable information than individual measurements of antioxidants. ${ }^{28,29}$ Thus, in our study, we used TAS as a marker of total

Table I The Light Microscope Data of Mice Skeletal Muscle (Mean \pm SE)

\begin{tabular}{|l|l|l|l|l|l|}
\hline & C Group (n=6) & I Group (n=6) & I/R Group (n=6) & I-I/R (n=6) & P** \\
\hline Inflammation & $0.00 \pm .0 .00^{*}$ & $0.17 \pm 0.17^{*}$ & $0.67 \pm 0.21$ & $0.17 \pm 0.17^{*}$ & 0.040 \\
Fibrosis & $0.00 \pm .0 .00$ & $0.00 \pm 0.00$ & $0.00 \pm 0.00$ & $0.00 \pm 0.00$ & - \\
Vascular dilatation & $0.00 \pm .0 .00$ & $0.00 \pm 0.00$ & $0.00 \pm 0.00$ & $0.00 \pm 0.00$ & - \\
Congestion & $0.00 \pm .0 .00^{*}$ & $0.00 \pm 0.00^{*}$ & $0.83 \pm 0.17$ & $0.50 \pm 0.22$ & 0.001 \\
Myositis injury & $0.00 \pm .0 .00^{*}$ & $0.00 \pm 0.00^{*}$ & $1.16 \pm 0.31$ & $0.50 \pm 0.22^{*}$ \\
\hline
\end{tabular}

Notes: 0: none, I: light, 2: severe. $\mathrm{P}^{* *}$ : Kruskal Wallis test, ${ }^{*} \mathrm{p}<0.05$ : Compared with I/R group. 


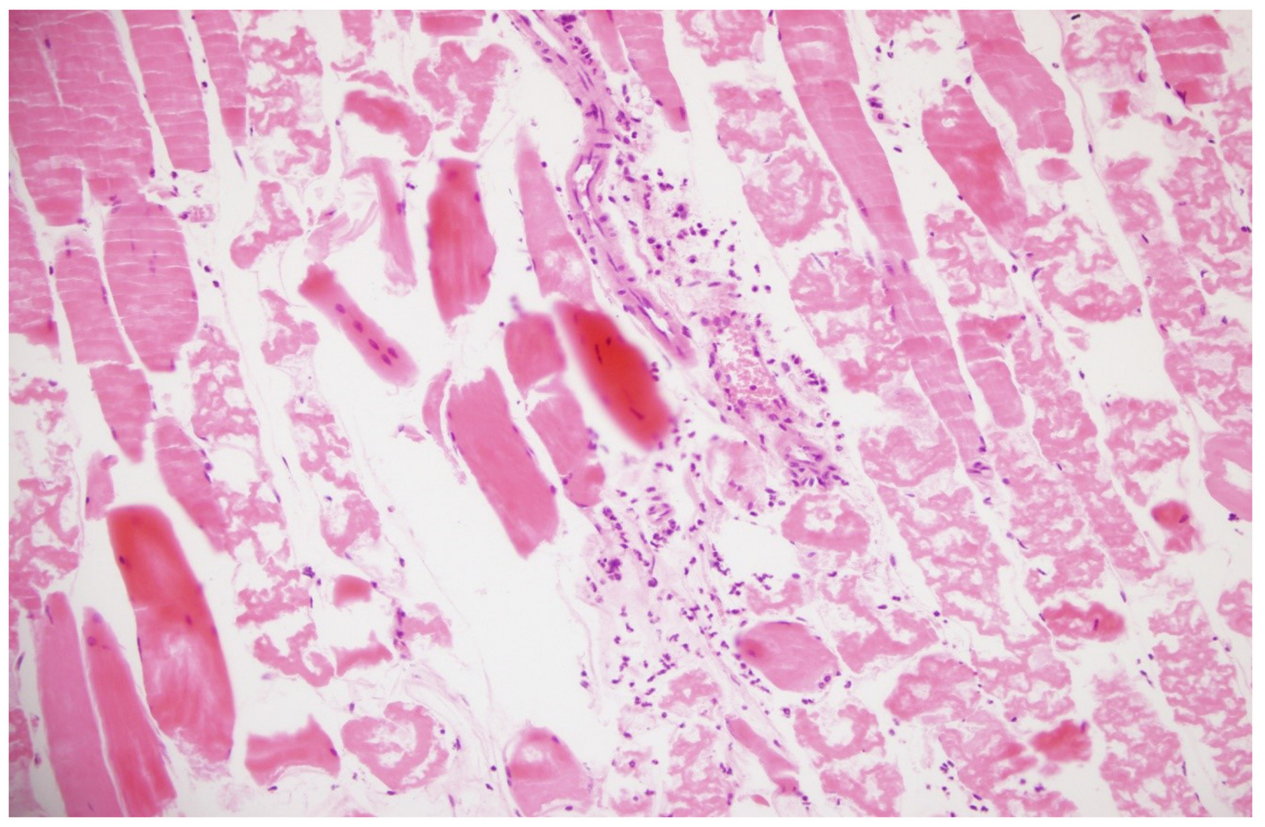

Figure 5 Prominent damage pattern is seen in most of the muscle fibers. There are also inflammatory cell infiltration sites between muscle fibers and significant congestion in veins $(\mathrm{HE}, 20 \mathrm{x})$.

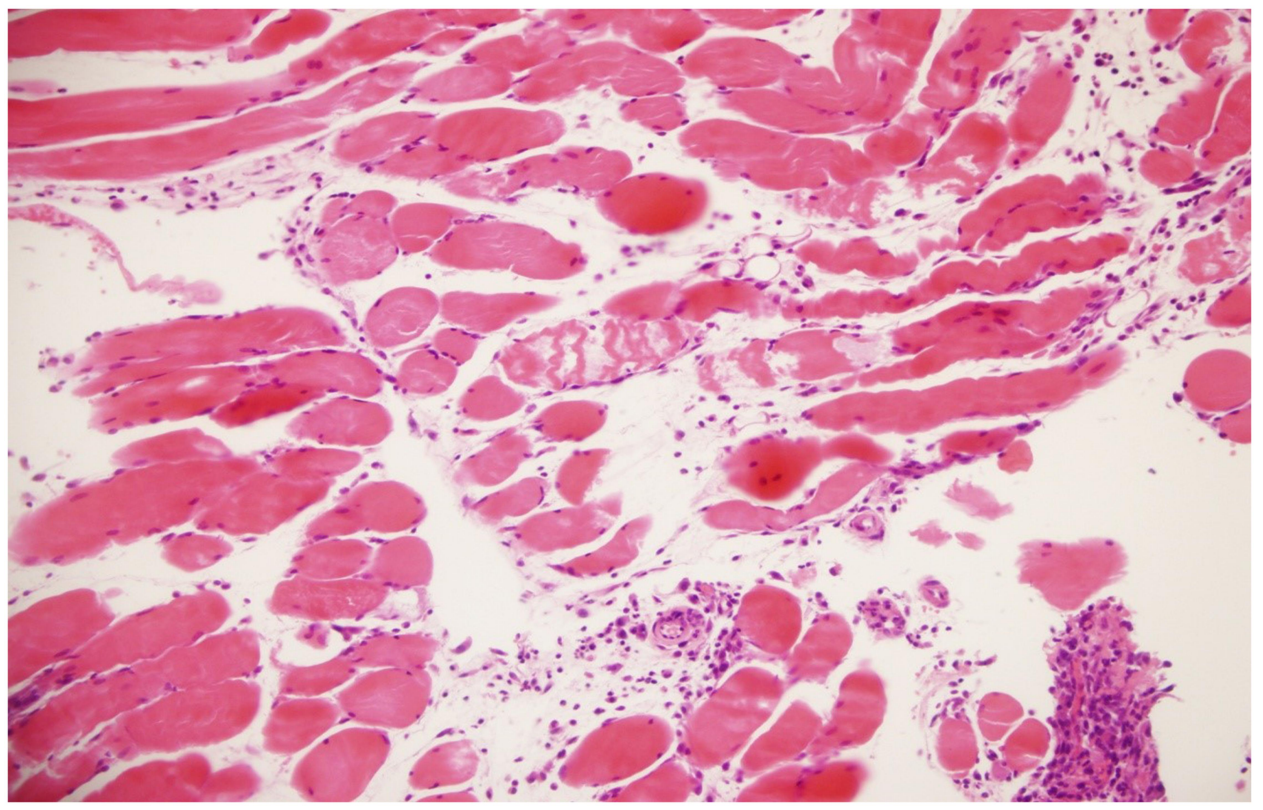

Figure 6 There are prominent focal acute necrotic change sites in muscular tissue sites and diffuse inflammatory cell infiltration (HE, 20x).

antioxidant protection against attack by free radicals and TOS as a marker of total oxidative stress. The TAS level was significantly higher in the $\mathrm{I} / \mathrm{R}$ group as compared with that in the control and $\mathrm{I}-\mathrm{I} / \mathrm{R}$ groups, which was in accordance with I/R-induced impairment of antioxidant activity, as reported previously. Kim et $\mathrm{al}^{30}$ found that vitamin $\mathrm{C}$ treatment at a dose of $2.5 \mathrm{mg}$ for $5 \mathrm{~d}$ increased the TAS during and after the treatment period. They found that
TAS levels were decreased in their study and attributed this finding to a decrease in antioxidant stress. The TOS level in the $\mathrm{I} / \mathrm{R}$ group in the present study was significantly higher than that in the control and $\mathrm{I}-\mathrm{I} / \mathrm{R}$ groups. Oxidative stress, which is the main actor of $I / R$ injury, was lower in the irisin-treated groups according to the TOS level.

Some pathophysiological processes in apoptosis events are related to the severity of $I / R^{31,32}$ The proportion of 
Bax to Bcl-2 reflects the triggering of apoptosis following the initiation process, and caspase- 3 antibody signaling is the main factor responsible for the acceleration of the apoptotic event. ${ }^{33,34}$ Previous research reported that irisin effectively decreased the cellular expression level of cleaved caspase-3, which, in turn, indicated that irisin administration may have a protective effect against $I / R$ damage of striated muscle tissue. In our study, we observed that irisin led to a reduction in caspase- 3 levels. This finding was in accordance with the previous study.

Significant differences were found between groups in terms of inflammation, myositis injury and congestion. Inflammation and myositis injury were significantly higher in the $I / R$ group than in the control, irisin, and $I-I / R$ groups. The congestion was significantly higher in the I/ $\mathrm{R}$ group than in the control and irisin groups. In addition, there was a significant between-group difference in the skeletal muscle cross-sections in our study.

In light of these data, we conclude that irisin has a protective effect against hind limb I/R-induced damage in skeletal muscle. To evaluate the protective effects of irisin against I/R-induced damage to various organs, studies are needed to establish different I/R times. Such studies could elucidate the protective effects of irisin, as well as the underlying mechanisms of tissue damage associated with $\mathrm{I} / \mathrm{R}$ injury.

\section{Disclosure}

The authors declare that they have no competing interests.

\section{References}

1. Kılıç Y, Özer A, Tatar T, et al. Effect of picroside II on hind limb ischemia reperfusion injury in rats. Drug Des Devel Ther. 2017;11:1917-1925. doi:10.2147/DDDT.S132401

2. Hensley K, Robinson KA, Gabbita SP, et al. Reactive oxygen species, cell signaling, and cell injury. Free Radic Biol Med. 2000;15(28):1456. doi:10.1016/S0891-5849(00)00252-5

3. Sirmali R, Armağan A, Öktem F, et al. Protective effects of erdosteine, vitamin $\mathrm{E}$, and vitamin $\mathrm{C}$ on renal injury induced by the ischemia-reperfusion of the hind limbs in rats. Turk J Med Sci. 2015;45:33-37. doi:10.3906/sag-1310-38

4. Erer D, Özer A, Demirtaş H, et al. Effects of alprostadil and iloprost on renal, lung and skeletal muscle injury following hind limb ischemia-reperfusion injury in rats. Drug Des Devel Ther. 2016;10:2651-2658. doi:10.2147/DDDT.S110529

5. Erer D, Dursun AD, Oktar GL, et al. The effects of iloprost on lung injury induced by skeletal muscle ischemia-reperfusion. Bratisl Med J. 2014;115(07):405-410. doi:10.4149/BLL_2014_080

6. Aydin S. Three new players in energy regulation: preptin, adropin and irisin. Peptides. 2014;56:94-110. doi:10.1016/j.peptides.2014.03.021

7. Boström P, Wu J, Jedrychowski MP, et al. A PGC1-alpha-dependent myokine that drives brown-fat-like development of white fat and thermogenesis. Nature. 2012;481(7382):463-468. doi:10.1038/nature 10777
8. Wang $\mathrm{H}$, Zhao YT, Zhang S, et al. Irisin plays a pivotal role to protect the heart against ischemia and reperfusion injury. J Cell Physiol. 2017;232(12):3775-3785. doi:10.1002/jcp.25857

9. Shao L, Meng D, Yang F, et al. Irisin-mediated protective effect on LPS-induced acute lung injury via suppressing inflammation and apoptosis of alveolar epithelial cells. Biochem Biophys Res Commun. 2017;487(2):194-200. doi:10.1016/j.bbrc.2017.04.020

10. Liu S, Du F, Li X, et al. Effects and underlying mechanisms of irisin on the proliferation and apoptosis of pancreatic $\beta$ cells. PLoS One. 2017;12(4):e0175498. doi:10.1371/journal.pone.0175498

11. Mazur-Bialy AI, Pochec' E, Zarawski M. Anti-inflammatory properties of irisin, mediator of physical activity, are connected with TLR4/ MyD88 signaling pathway activation. Int J Mol Sci. 2017;18(4): E701. doi:10.3390/ijms18040701

12. Mazur-Bialy AI, Bilski J, Pochec E, et al. New insight into the direct anti-inflammatory activity of a myokine, irisin against proinflammatory activation of adipocytes. Implication for exercise in obesity. J Physiol Pharmacol. 2017;68(2):243-251.

13. Asadi Y, Gorjipour F, Behrouzifar S, et al. Irisin peptide protects brain against ischemic injury through reducing apoptosis and enhancing BDNF in a rodent model of stroke. Neurochem Res. 2018;43 (8):1549-1560. doi:10.1007/s11064-018-2569-9

14. Park MJ, Kim DI, Choi JH, et al. New role of irisin in hepatocytes: the protective effect of hepatic steatosis in vitro. Cell Signal. 2015;27 (9):1831-1839. doi:10.1016/j.cellsig.2015.04.010

15. Colaianni G, Mongelli T, Cuscito C, et al. Irisin prevents and restores bone loss and muscle atrophy in hind-limb suspended mice. Sci Rep. 2017;7(1):2811. doi:10.1038/s41598-017-02557-8

16. Kruidering M, Evan GI. Caspase-8 in apoptosis: the beginning of "the end"? IUBMB Life. 2000;50(2):85-90. doi:10.1080/713803693

17. Huh JY, Panagiotou G, Mougios V, et al. FNDC5 and irisin in humans: I. predictors of circulating concentrations in serum and plasma and II. mRNA expression and circulating concentrations in response to weight loss and exercise. Metabolism. 2012;61 (12):1725-1738. doi:10.1016/j.metabol.2012.09.002

18. Polyzos SA, Kountouras J, Shields K, et al. Irisin: a renaissance in metabolism? Metabolism. 2013;62(8):1037-1044. doi:10.1016/j. metabol.2013.04.008

19. Wrann CD, White JP, Salogiannnis J, et al. Exercise induces hippocampal BDNF through a PGC-1 $\alpha /$ FNDC5 pathway. Cell Metab. 2013;18(5):649-659. doi:10.1016/j.cmet.2013.09.008

20. Zhu D, Wang $\mathrm{H}$, Zhang J, et al. Irisin improves endothelial function in type 2 diabetes through reducing oxidative/nitrative stresses. $J \mathrm{Mol}$ Cell Cardiol. 2015;87:138-147. doi:10.1016/j.yjmcc.2015.07.015

21. Bi J, Zhang J, Ren Y, et al. Irisin alleviates liver ischemia-reperfusion injury by inhibiting excessive mitochondrial fission, promoting mitochondrial biogenesis and decreasing oxidative stress. Redox Biol. 2019;20:296-306. doi:10.1016/j.redox.2018.10.019

22. Zhao G, Zhang X, Xu P, et al. The protective effect of Irisin against ischemia-reperfusion injury after perforator flap grafting in rats. Injury. 2018;49(12):2147-2153. doi:10.1016/j.injury.2018.09.054

23. Chen $\mathrm{K}, \mathrm{Xu} \mathrm{Z}$, Liu Y, et al. Irisin protects mitochondria function during pulmonary ischemia/reperfusion injury. Sci Transl Med. 2017;9(418):eaao6298. doi:10.1126/scitranslmed.aao6298

24. Halliwell B, Gutteridge JMC. Free Radicals in Biology and Medicine. 3rd ed. New York: Oxford University Press; 1999: 246-350.

25. McCord JM. Free radicals and myocardial ischemia: overview and outlook. Free Radic Biol Med. 1988;4(1):9-14. doi:10.1016/08915849(88)90005-6

26. Mozaffari MS, Liu JY, Abebe W, et al. Mechanisms of load dependency of myocardial ischemia reperfusion injury. Am $J$ Cardiovasc Dis. 2013;3(4):180-196.

27. Turer AT, Hill JA. Pathogenesis of myocardial ischemia-reperfusion injury and rationale for therapy. Am J Cardiol. 2010;106(3):360-368. doi:10.1016/j.amjcard.2010.03.032 
28. Zhang M, Fangfang P, Zhang R, et al. The antioxidant effect of picroside II and the optimizing of therapeutic dose and time window in cerebral ischemic injury in rats. Merit Res $J$ Pharm Pharm Sci. 2013;1:1-7.

29. Ghiselli A, Serafini M, Natella F, et al. Total antioxidant capacity as a tool to assess redox status: critical view and experimental data. Free Radic Biol Med. 2000;29(11):1106-1114. doi:10.1016/S0891-5849 (00)00394-4

30. Kim JH, Kim YC, Nahm FS, et al. The therapeutic effect of vitamin $\mathrm{C}$ in an animal model of complex regional pain syndrome produced by prolonged hindpaw ischemia-reperfusion in rats. Int $\mathrm{J}$ Med Sci. 2017;14(1):97-101. doi:10.7150/ijms.17681

31. Erel O. A novel automated direct measurement method for total antioxidant capacity using a new generation, more stable ABTS radical cation. Clin Biochem. 2004;37(4):277-285. doi:10.1016/j. clinbiochem.2003.11.015
32. Mallick IH, Yang W, Winslet MC, et al. Ischemia-reperfusion injury of the intestine and protective strategies against injury. Dig Dis Sci. 2004;49(9):1359-1377. doi:10.1023/B:DDAS.0000042232.98927.91

33. Yang B, Chen Y, Long YH, et al. Intestinal and limb ischemic preconditioning provides a combined protective effect in the late phase, but not in the early phase, against intestinal injury induced by intestinal ischemia-reperfusion in rats. Shock. 2018;49 (5):596-603. doi:10.1097/SHK.0000000000000956

34. Zu G, Zhou T, Che N, et al. Salvianolic acid a protects against oxidative stress and apoptosis induced by intestinal ischemia-reperfusion injury through activation of $\mathrm{Nrf} 2 / \mathrm{HO}-1$ pathways. Cell Physiol Biochem. 2018;49(6):2320-2332. doi:10. $1159 / 000493833$

\section{Publish your work in this journal}

Drug Design, Development and Therapy is an international, peerreviewed open-access journal that spans the spectrum of drug design and development through to clinical applications. Clinical outcomes, patient safety, and programs for the development and effective, safe, and sustained use of medicines are a feature of the journal, which has also been accepted for indexing on PubMed Central. The manuscript management system is completely online and includes a very quick and fair peer-review system, which is all easy to use. Visit http://www. dovepress.com/testimonials.php to read real quotes from published authors. 